\title{
Readmissions Within 48 Hours of Discharge: Reasons, Risk Factors, and Potential Improvements
}

\author{
Fabian Grass, M.D. ${ }^{1,2}$ • Jacopo Crippa, M.D. ${ }^{1}$ • Jenna K. Lovely, Pharm.D., R.Ph., B.C.P.S. ${ }^{3}$ \\ James Ansell, M.B.B.Ch., M.D. ${ }^{1}$ Kevin T. Behm, M.D. ${ }^{1}$ Pietro Achilli, M.D. ${ }^{1}$ \\ Martin Hübner, M.D. ${ }^{2}$ Scott R. Kelley, M.D., M.Sc. ${ }^{1}$ Kellie L. Mathis, M.D., M.Sc. ${ }^{1}$ \\ Eric J. Dozois, M.D. ${ }^{1}$ David W. Larson, M.D., M.B.A. ${ }^{1}$ \\ 1 Division of Colon and Rectal Surgery, Mayo Clinic, Rochester, Minnesota \\ 2 Department of Visceral Surgery, Lausanne University Hospital CHUV, Lausanne, Switzerland \\ 3 Hospital Pharmacy Services, Mayo Clinic, Rochester, Minnesota
}

BACKGROUND: Hospital readmission rate is an important quality metric and has been recognized as a key measure of hospital value-based purchasing programs.

OBJECTIVE: This study aimed to assess the risk factors for hospital readmission with a focus on potentially preventable early readmissions within 48 hours of discharge.

DESIGN: This is a retrospective cohort study.

SETTINGS: This study was conducted at a tertiary academic facility with a standardized enhanced recovery pathway.

PATIENTS: Consecutive patients undergoing elective major colorectal resections between 2011 and 2016 were included.

MAIN OUTCOME MEASURES: Univariable and multivariable risk factors for overall and early $(<48$ hours) readmissions were identified. Specific surgical and medical reasons for readmission were compared between early and late readmissions.

RESULTS: In total, 526 of 4204 patients (12.5\%) were readmitted within 30 days of discharge. Independent

Funding/Support: Fabian Grass, M.D., was supported by the Société Académique Vaudoise, Lausanne, Switzerland and by the SICPA Foundation, Lausanne, Switzerland.

Financial Disclosures: None reported.

Correspondence: David W. Larson, M.D., M.B.A., Mayo Clinic, 200 First Street SW, Rochester, MN 55905. E-mail: Larson.David2@mayo.edu.

Dis Colon Rectum 2020; 63: 1142-1150

DOI: $10.1097 /$ DCR.0000000000001652

(c) The ASCRS 2020 risk factors were ASA score ( $\geq 3$; OR, $1.5 ; 95 \%$ CI, 1.1-2), excess perioperative weight gain (OR, 1.7; 95\% CI, 1.3-2.3), ileostomy (OR, 1.4; 95\% CI, 1-2), and transfusion (OR, 2; 95\% CI, 1.4-3), or reoperation (OR, 11.4; 95\% CI, 7.4-17.5) during the index stay. No potentially preventable risk factor for early readmission (128 patients, $24.3 \%$ of all readmissions, $3 \%$ of total cohort) was identified, and index hospital stay of $\leq 3$ days was not associated with increased readmission (OR, 0.9; 95\% CI, $0.7-1.2)$. Although ileus and small-bowel obstruction (early: $43.8 \%$ vs late: $15.5 \%, p<0.001$ ) were leading causes for early readmissions, deep infections (3.9\% vs $16.3 \%, p<0.001)$ and acute kidney injury ( $0 \%$ vs $5 \%$, $p=0.006$ ) were mainly observed during readmissions after 48 hours.

LIMITATIONS: Risk of underreporting due to loss of follow-up and the potential co-occurrence of complications were limitations of this study.

CONCLUSIONS: Early hospital readmission was mainly due to ileus or bowel obstruction, whereas late readmissions were related to deep infections and acute kidney injury. A suspicious attitude toward potential ileus-related symptoms before discharge and dedicated education for ostomy patients are important. A short index hospital stay was not associated with increased readmission rates. See Video Abstract at http://links.lww. com/DCR/B237.

REINGRESOS DENTRO DE LAS 48 HORAS POSTERIORES AL ALTA: RAZONES, FACTORES DE RIESGO Y POSIBLES MEJORAS

ANTECEDENTES: La tasa de reingreso hospitalario es una métrica de calidad importante y ha sido reconocida como una medida clave de los programas hospitalarios de compras basadas en el valor. 
OBJETIVO: Evaluar los factores de riesgo para el reingreso hospitalario con énfasis en reingresos tempranos potencialmente prevenibles dentro de las 48 horas posteriores al alta.

DISEÑO: Estudio de cohorte retrospectivo.

ESCENARIO: Institución académica terciaria con programa de recuperación mejorada estandarizado.

PACIENTES: Pacientes consecutivos sometidos a resecciones colorrectales mayores electivas entre 2011 y 2016.

PRINCIPALES MEDIDAS DE RESULTADO: Se identificaron factores de riesgo uni y multivariables para reingresos totales y tempranos ( $<48$ horas). Se compararon razones médicas y quirúrgicas específicas para el reingreso entre reingresos tempranos y tardíos.

RESULTADOS: En total, 526/4204 pacientes (12,5\%) fueron readmitidos dentro de los 30 días posteriores al alta. Los factores de riesgo independientes fueron puntuación ASA ( $\geq 3$, OR 1.5; IC 95\% 1.1-2), aumento de peso perioperatorio excesivo (OR 1.7; IC 95\% 1.3-2.3), ileostomía (OR 1.4, IC 95\%: 1-2) y transfusión (OR 2, IC 95\% 1.4-3) o reoperación (OR 11.4; IC 95\% 7.4-17.5) durante la estadía índice. No se identificó ningún factor de riesgo potencialmente prevenible para el reingreso temprano (128 pacientes, $24.3 \%$ de todos los reingresos, $3 \%$ de la cohorte total), y la estadía hospitalaria índice de $\leq 3$ días no se asoció con un aumento en el reingreso (OR 0.9; IC 95\% 0.7-1.2) Mientras que el íleo / obstrucción del intestino delgado (temprano: $43.8 \%$ vs. tardío: $15.5 \%$, $p<0.001)$ fueron las principales causas de reingresos tempranos, infecciones profundas $(3.9 \%$ vs $16.3 \%$, $p<0.001$ ) y lesión renal aguda ( 0 vs $5 \%, p=0.006$ ) se observaron principalmente durante los reingresos después de 48 horas.

LIMITACIONES: Riesgo de subregistro debido a la pérdida en el seguimiento, posible co-ocurrencia de complicaciones.

CONCLUSIONES: El reingreso hospitalario temprano se debió principalmente a íleo u obstrucción intestinal, mientras que los reingresos tardíos se relacionaron con infecciones profundas y lesión renal aguda. Es importante tener una actitud suspicaz hacia los posibles síntomas relacionados con el íleo antes del alta y una educación específica para los pacientes con ostomía. La estadía hospitalaria índice corta no se asoció con mayores tasas de reingreso. Consulte Video Resumen en http:// links.lww.com/DCR/B237. (Traducción-Dr. Jorge Silva Velazco)

KEY WORDS: Colorectal; Enhanced recovery; Prevention; Readmission.
E nhanced recovery pathways (ERPs) for colorectal surgery have been associated with decreased morbidity, length of stay, and costs in meta-analyses of numerous randomized controlled trials. ${ }^{1-3}$ Readmissions have been commonly recognized as important cost drivers, ${ }^{4}$ and several large-scale studies using national or statewide data focused on identifying potentially targetable predictors of hospital readmission. ${ }^{4-8}$ However, institution-specific discrepancies due to variable care protocols, discharge criteria, or surgical settings may impede uncritical extrapolation and application of the results. Moreover, large patient cohorts are required to identify less common and potentially preventable reasons for readmission that can help focus researchers on specific outcomes of interest, such as very early readmissions.

Since the implementation of ERP as a standard of care in 2011 for the Division of Colon and Rectal Surgery, several institutional publications have reported encouraging short-term results. ${ }^{9-11}$ However, the impact of significantly shortened hospital stay (median 3 days) and its association with potentially avoidable readmissions have not yet been investigated in our facility. In this context, the quality metric of readmission requires critical assessment.

The present study aimed to identify predictors of hospital readmission, with particular focus on the impact of a short ( $\leq 3$ days) index hospital stay. Furthermore, risk factors for early ( $<48$ hours after discharge) readmissions were analyzed to seek potential improvements in patient care.

\section{METHODS}

\section{Patients}

This is a retrospective cohort study of consecutive adult ( $\geq 18$ years) patients who underwent major (open or laparoscopic, under general anesthesia) elective colorectal resections over a 6-year study period (2011-2016) at a tertiary academic teaching hospital. Indications for surgery were stratified in malignancy, IBD, and other benign conditions. All patients were treated within a standardized, comprehensive ERP, which was implemented in 2010 and accepted as the standard of practice as of January 2011 in the Division of Colon and Rectal Surgery. Specifics of the pathway and contents of the prospectively maintained institutional database have been previously published with focus on compliance and short-term outcomes. ${ }^{9} 10,12$ The institutional ERP features standardized dismissal criteria including pharmacist medication reconciliation with the surgical team. ${ }^{9,13}$ Discharge criteria include patient tolerating oral diet, ambulating (at least 6 hours/day or back to baseline ambulation status), adequate pain control with oral medications, and no evidence of complications by the time of dismissal. Ileus-preventing measures include early ambulation and realimentation, an opioid-sparing pain management strategy, restrictive fluid management, and 
magnesium oxide. Even though evaluated on a daily basis, return of bowel movements (flatus or stool) was not systematically recorded because it was not considered a mandatory discharge criterion. Laboratory studies were not part of the discharge criteria either. A checklist for consistency in medication reconciliation and overall dismissal criteria and preparedness was utilized. ${ }^{13}$ This study was approved by the Institutional Review Board.

Over the entire study period, a prospectively maintained institutional database included patient demographics, surgical details, and postoperative outcomes during the index hospitalization. Furthermore, compliance with ERP-related items was analyzed, with particular focus on restrictive intraoperative fluid management in line with the recommendations of the American Society of Enhanced Recovery, ${ }^{14}$ multimodal analgesia favoring intrathecal technique, ${ }^{15}$ early resumption of a normal diet, ${ }^{16}$ and ambulation. Specific surgical 30-day outcomes were postoperative (paralytic) ileus (defined as need for nasogastric tube reinsertion); small-bowel obstruction (defined as obstruction needing surgical reintervention); bleeding complication (defined as need for any transfusion with packed red blood cells during index stay); surgical site infection (SSI), stratified according to the definitions of the Centers for Disease Control and Prevention National Nosocomial Infection Surveillance criteria into superficial incisional, deep incisional, and organ space infection ${ }^{17}$; and clinically or radiologically confirmed anastomotic leak. Of note, all types of SSI were considered when assessing specific reasons for readmission, whereas only clinically relevant SSIs needing invasive management (either percutaneous or surgical) were retained for risk factors analysis. Further assessed were reoperation rates and length of postprocedure stay, as well as discharge to home as opposed to a skilled rehabilitation facility. All postoperative outcomes were related to the index hospital stay, whereas reasons for readmission were independently assessed and retrieved from administrative data.

\section{Outcomes}

The primary outcome was 30-day readmission after the index hospital stay, defined as unplanned readmission by the time of hospital discharge to either the index or an independent facility. Although emergency department visits were retained, control visits by general care practitioners were not accounted for. Readmissions were retrieved from administrative data of Mayo or the respective institution. For long-distance referrals without 30-day follow-up at Mayo, systematic phone calls were performed at 1 month. As a general rule, severe surgery-related conditions warranted a transfer to the index institution.

Demographic, surgical, and ERP-related details were compared between readmitted and nonreadmitted patients to identify predictors of hospital readmission. Sub- group analysis of early readmitted patients ( $<48$ hours after hospital discharge) was performed to identify specific (and potentially avoidable) risk factors for early readmission. Furthermore, early readmissions ( $<48$ hours) were compared with later readmissions ( $>48$ hours) regarding ERP compliance and reasons for readmission. Index hospital stay of $\leq 3$ days, revealed as median hospital stay by several former institutional publications and representing a target for elective surgery, ${ }^{9,10,18,19}$ was analyzed as a confounder to assess a potential association of early hospital discharge and readmission.

Reasons for hospital readmission were categorized as surgical, medical, or infectious according to the main complication or condition that led to readmission. Infectious complications were further divided in medical infectious and surgical infectious complications (including anastomotic leaks, SSIs, and bowel perforations at distant sites). Several complications per readmitted patient (ie, dehydration and acute kidney injury) were possible. Dehydration related to high stoma output was specifically assessed and grouped together. Furthermore, complications that led to readmission were stratified according to the ClavienDindo classification scale to identify major complications ( $\geq$ grade IIIb) ${ }^{20}$ with specific assessment of readmissions needing reoperation. Specific surgical and medical complications have been defined according to previous institutional publications and are consistent with definitions outlined by the American College of Surgeons National Surgical Quality Improvement Project., ${ }^{912,21}$

\section{Statistical Analysis}

Descriptive statistics are reported as median (interquartile range) and range or mean $\pm \mathrm{SD}$, as appropriate, for continuous variables and absolute or relative frequencies for categorical variables. Continuous variables were compared using the Student $t$ test; categorical variables were compared using the Fisher exact $\left(\chi^{2}\right)$ test. All tests were 2 -sided, and a $p$ value of $<0.05$ was considered statistically significant.

Independent predictors for overall and early $(<48$ hours) hospital readmission were identified through multinominal logistic regression of significant univariate risk factors to provide adjusted estimations of the odds ratio. Items that were inconsistently assessed (ie, laboratory parameters) were excluded from multivariable analysis. Data analysis was performed with the Statistical Software for the Social Sciences SPSS Advanced Statistics 22 (IBM Software Group, 200 W Madison St, Chicago, IL 60606).

\section{RESULTS}

\section{Patients}

Of 4204 patients, $526(12.5 \%)$ were readmitted within 30 days of discharge. Of these, 128 patients (24.3\%) were 
readmitted within 48 hours of discharge (3\% of total). Median time to readmission for the whole cohort was 5 (interquartile range, 4-11) days after discharge. Table 1 gives an overview on demographics of the cohort; readmitted patients were preponderantly male and had higher ASA scores. Furthermore, differences in baseline preoperative laboratory values (drawn within 7 days of surgery) were observed. Preoperative hypoalbuminemia as surrogate for malnutrition $(29.9 \%$ vs $18.5 \%, p<0.001)$, preoperative anemia $(57.7 \%$ vs $40.3 \%, p<0.001)$, and preoperative leukocytosis $(15.8 \%$ vs $11.2 \%, p=0.004)$ were preponderant in subsequently readmitted patients. Table 2 details surgery-associated and postoperative outcome data. Readmission rates were higher in patients undergoing more extensive procedures, such as rectal resection and total colectomy. Readmission rates according to surgical procedure were as follows: $7.1 \%$ after segmental/transverse colectomy, $9.2 \%$ after left colectomy, $10.1 \%$ after right colectomy, $14.9 \%$ after rectal resection, and $17.5 \%$ after total colectomy. No important differences however were observed between patients who had cancer (12.6\%), patients with IBD (13.0\%), and patients experiencing other benign pathologies $(11.3 \%)$. The readmission rate of patients with any new ileostomy (end or diverting) was $18.8 \%$, whereas the readmission rate was $17.4 \%$ in patients with a temporary diversion. Long procedures, open approach, and perioperative fluid overload as surrogates for surgical difficulty were associated with increased readmission rates. Several specific surgical complications during the index hospital stay led to increased readmission rates, as specified in Table 2 .

\section{Independent Predictors of Readmission}

Table 3 displays multivariable risk factors for overall and early ( $<48$ hours) readmission. Independent predictors for hospital readmission within 30 days were ASA score ( $\geq 3$; OR, 1.5; 95\% CI, 1.1-2), excess perioperative weight gain (OR, 1.7; 95\% CI, 1.3-2.3), ileostomy (OR, 1.4; 95\% $\mathrm{CI}, 1-2)$, perioperative transfusion $(\mathrm{OR}, 2 ; 95 \% \mathrm{CI}, 1.4-3)$, and reoperation (OR, 11.4; 95\% CI, 7.4-17.5) during the index hospital stay. No potentially preventable risk factors for early ( $<48$ hours) hospital readmission (more common after total colectomy and reoperation) were identified. In particular, an index hospital stay of $\leq 3$ days was neither associated with increased overall $(9.5 \%)$ nor early readmission rate $(2.9 \%)$. Because of the strong impact of severe adverse events on readmission, subgroup analysis of patients without occurrence of an anastomotic leak, SSI needing invasive treatment, any transfusion requirement, and reoperation was performed. In these 3463 patients, the readmission rate of patients discharged within 3 days of surgery was $6.7 \%(119 / 1768)$, whereas the rate was $10.3 \%$ $(175 / 1695)$ in patients discharged after 3 days $(p<0.001)$.

\section{Early (<48 Hours) Versus Late ( $>48$ Hours) Readmissions}

Although ileus and small-bowel obstruction (early: $43.8 \%$ vs late: $15.5 \%, p<0.001$ ) were leading causes for early readmissions $(\mathrm{n}=128)$, surgical infectious complications, in particular organ space infections (3.9\% vs $16.3 \%$, $p<0.001)$, as well as acute kidney injury ( $0 \%$ vs $5 \%$, $p=0.006$ ) due to dehydration (high stoma output), were mainly observed during later readmissions after 48 hours, as outlined in Table 4 . With $1.1 \%$, the 30 -day mortality rate of readmitted patients was higher than for the remaining cohort $(0.5 \%, p=0.039)$. Compliance with ERP differed significantly between readmitted and nonreadmitted patients regarding the use of intrathecal analgesia $(p=0.001)$, postoperative day 0 fluids $<3 \mathrm{~L}(p=0.013)$, ordering of a (normal) ERP diet $(p<0.001)$, postoperative day 2 weight gain $<2.5 \mathrm{~kg}(p<0.001)$, discharge to

TABLE 1. Demographics

\begin{tabular}{|c|c|c|c|c|}
\hline Item & $\begin{array}{c}\text { All } \\
(n=4204)\end{array}$ & $\begin{array}{l}\text { Readmission } \\
(n=526)\end{array}$ & $\begin{array}{c}\text { No readmission } \\
\quad(n=3678)\end{array}$ & $p$ \\
\hline Age, mean \pm SD & $55.6 \pm 18$ & $53.3 \pm 19$ & $55.9 \pm 17.9$ & 0.003 \\
\hline Age $\geq 70$ y, n (\%) & $1017(24.2)$ & $119(22.6)$ & $920(24.4)$ & 0.384 \\
\hline $\mathrm{BMI}\left(\mathrm{kg} / \mathrm{m}^{2}\right)$, mean $\pm \mathrm{SD}$ & $27.4 \pm 6.5$ & $27.1 \pm 6.4$ & $27.5 \pm 6.5$ & 0.299 \\
\hline $\mathrm{BMI} \geq 30 \mathrm{~kg} / \mathrm{m}^{2}, \mathrm{n}(\%)$ & $1171(27.8)$ & $151(28.7)$ & $1020(27.7)$ & 0.640 \\
\hline ASA group $(\geq 3), n(\%)$ & $1182(28.1)$ & $191(36.3)$ & $991(26.9)$ & $<0.001$ \\
\hline$<3.5 \mathrm{~g} / \mathrm{dL}, \mathrm{n}(\%)$ & $338 / 1685(20)$ & 69/231 (29.9) & $269 / 1528(18.5)$ & $<0.001$ \\
\hline Preoperative hemoglobin (g/dL) & $12.2 \pm 2.2$ & $11.1 \pm 2.2$ & $12.4 \pm 2$ & 0.001 \\
\hline$<12 \mathrm{~g} / \mathrm{dL}$ & $357 / 830(43)$ & $75 / 130(57.7)$ & $282 / 700(40.3)$ & $<0.001$ \\
\hline Preoperative creatinine (mg/dL) & $0.94 \pm 0.38$ & $1 \pm 0.84$ & $0.89 \pm 0.33$ & 0.024 \\
\hline Preoperative WBC count $\left(\times 10^{3} / \mu \mathrm{L}\right)$ & $7.6 \pm 4.3$ & $8.4 \pm 7.7$ & $7.5 \pm 3.5$ & 0.013 \\
\hline$>11 \times 10^{3} / \mu \mathrm{L}$ & $451 / 3830(11.8)$ & $77 / 487(15.8)$ & $374 / 3343(11.2)$ & 0.004 \\
\hline
\end{tabular}

Baseline demographic parameters of readmitted $(n=526)$ and nonreadmitted patients $(n=3678)$. Bold characters indicate significant values $(p<0.05)$.

WBC $=$ white blood cell count. 
TABLE 2. Surgical/perioperative details and postoperative recovery

\begin{tabular}{|c|c|c|c|c|}
\hline Item & $\begin{array}{c}\text { All } \\
(n=4204)\end{array}$ & $\begin{array}{l}\text { Readmission } \\
\quad(n=526)\end{array}$ & $\begin{array}{c}\text { No readmission } \\
\quad(n=3678)\end{array}$ & $p$ \\
\hline \multicolumn{5}{|l|}{ Indication, n (\%) } \\
\hline Malignancy & $2733(65)$ & $345(65.6)$ & $2388(64.9)$ & 0.766 \\
\hline IBD & $845(20.1)$ & $110(20.9)$ & $735(20.0)$ & 0.619 \\
\hline Other benign conditions & $626(14.9)$ & $71(13.5)$ & $555(15.1)$ & 0.337 \\
\hline Open surgery & $1898(45.1)$ & $266(50.6)$ & $1632(44.4)$ & 0.009 \\
\hline \multicolumn{5}{|l|}{ Procedure, n (\%) } \\
\hline Left colectomy & $1019(24.2)$ & $94(17.9)$ & $925(25.1)$ & $<0.001$ \\
\hline Right colectomy & $1047(24.9)$ & $106(20.2)$ & $941(25.6)$ & 0.007 \\
\hline Segmental/transverse colectomy & $98(2.3)$ & $7(1.3)$ & $91(2.5)$ & 0.122 \\
\hline Total colectomy & $561(13.3)$ & $98(18.6)$ & $463(12.6)$ & $<0.001$ \\
\hline Rectal resection & $1479(35.2)$ & $221(42)$ & $1258(34.2)$ & 0.001 \\
\hline Any ileostomy, n (\%) & $1376(32.7)$ & $258(49)$ & $1118(30.4)$ & $<0.001$ \\
\hline Temporary diverting & $849(20.2)$ & $148(28.1)$ & $701(19.1)$ & $<0.001$ \\
\hline Operation duration (min), mean \pm SD & $200 \pm 98$ & $226 \pm 118$ & $197 \pm 95$ & $<0.001$ \\
\hline Operation duration $>180 \mathrm{~min}, \mathrm{n}(\%)$ & $2087(49.6)$ & $314(59.7)$ & $1773(48.2)$ & $<0.001$ \\
\hline POD 0 IV fluids $>3 \mathrm{~L}, \mathrm{n}(\%)$ & $1918(45.6)$ & $267(50.8)$ & $1651(44.9)$ & 0.013 \\
\hline POD 2 weight gain $>2.5 \mathrm{~kg}, \mathrm{n}(\%)$ & $793 / 1393(56.9)$ & $209 / 312(67)$ & $584 / 1081(54)$ & $<0.001$ \\
\hline \multicolumn{5}{|l|}{ Index hospital stay (days) } \\
\hline Median (IQR) & $4(3-6)$ & $4.5(3-8)$ & $4(3-6)$ & $<0.001$ \\
\hline$\leq 3$ days, $\mathrm{n}(\%)$ & $1910(45.4)$ & $181(34.4)$ & $1729(47)$ & $<0.001$ \\
\hline \multicolumn{5}{|l|}{ Surgical complication (index stay), n (\%) } \\
\hline Any transfusion & $523(12.4)$ & $126(24)$ & $397(10.8)$ & $<0.001$ \\
\hline SSI needing invasive treatment & $229(5.4)$ & $56(10.6)$ & $173(4.7)$ & 0.006 \\
\hline Postoperative ileus & $376(8.9)$ & $65(12.4)$ & $311(8.5)$ & 0.005 \\
\hline Anastomotic leak & $114(2.7)$ & $31(5.9)$ & $83(2.3)$ & $<0.001$ \\
\hline Reoperation & $247(5.9)$ & $132(25.1)$ & $115(3.1)$ & $<0.001$ \\
\hline
\end{tabular}

Surgical and postoperative recovery parameters of readmitted $(n=526)$ and nonreadmitted patients $(n=3678)$. Bold characters indicate significant values $(p<0.05)$. $\mathrm{IQR}=$ interquartile range; IV = intravenous; $\mathrm{POD}=$ postoperative day; $\mathrm{SSI}=$ surgical site infection.

home ( $p=0.001)$, and index length of stay (LoS) $\leq 3$ days $(p<0.001)$. A higher proportion of patients with an index hospital stay of $\leq 3$ days was observed in the early readmitted group than in the group with later readmissions, whereas all other items did not differ significantly between these 2 comparative groups ( $43 \%$ vs $31.7 \%, p=0.024$; Fig. 1 ).

\section{DISCUSSION}

This single-center analysis of a large, unselected cohort of patients undergoing major colorectal resection within a highly standardized ERP revealed 3 important findings. One, a quarter of all readmissions occurred within 48 hours of discharge; however, no distinctive patterns could be identified to potentially avoid these readmissions. Two, a short index hospital stay ( $\operatorname{LoS} \leq 3$ days) was not associated with an increased readmission rate. This is important considering the significant LoS reduction for major colorectal resections within our institution since ERP implementation. Third, readmissions seemed to be associated with a complicated recovery during the index stay rather than the type of surgery; however, patients with a new ileostomy were particularly prone to be readmitted.

Hospital readmission rate is an important quality metric and has been recognized as a key measure of hospital value-based purchasing programs. ${ }^{22-24}$ Readmissions have important implications for patients and health care, in general, considering important associated costs. Largescale studies revealed costs of $\$ 7030$ to $\$ 9000$ for readmission care. ${ }^{4,25}$ Furthermore, median combined direct hospital cost was more than 2 times higher for readmitted than for nonreadmitted patients. ${ }^{26}$ Readmission to nonindex hospitals may lead to higher mortality and morbidity than readmission to index hospitals, which is particularly important to consider for high-volume hospitals with nationwide patient accrual, such as our facility. ${ }^{8,27}$ Since the implementation of ERP as a Division standard, critical assessment of readmissions and specifically LoS reduction had yet to be performed.

The observed overall readmission rate of $12.5 \%$ compares well with previous reports. ${ }^{6,7,28,29}$ The present study revealed surrogates for impaired patient condition and surgical difficulty, such as ASA score ${ }^{30}$ and postoperative weight gain, as "to be expected" independent risk factors. However, more predictive than the exhaustive list of demographic-, disease-, or surgery-related items was the postoperative course itself, as highlighted by the strong association of specific postoperative complications, reoperation, and readmission. Similar observations were made in a National Surgical Quality Improvement Project analysis by Bartlett et $\mathrm{al}^{6}$; whereas the readmission rate in patients experiencing a postoperative complication occurrence 
TABLE 3. Multivariable analysis

\begin{tabular}{|c|c|c|c|c|}
\hline \multirow[b]{2}{*}{ Item } & \multicolumn{2}{|c|}{$\begin{array}{l}\text { Any readmission } \\
\quad(n=526)\end{array}$} & \multicolumn{2}{|c|}{$\begin{array}{l}\text { Early readmission } \\
\qquad(n=128)\end{array}$} \\
\hline & Univariate & Multivariable & Univariate & Multivariable \\
\hline ASA group $(\geq 3)$ & $1.57(1.30-1.90)$ & $1.50(1.10-2.05)$ & $1.32(0.91-1.92)$ & - \\
\hline Open surgery & $1.29(1.08-1.55)$ & $1.16(0.87-1.57)$ & $0.98(0.68-1.39)$ & - \\
\hline Left colectomy & $0.69(0.55-0.86)$ & $1.21(0.31-4.74)$ & $0.87(0.57-1.33)$ & - \\
\hline Rectal resection & $1.40(1.17-1.68)$ & $1.08(0.28-4.23)$ & $0.83(0.57-1.22)$ & - \\
\hline Any ileostomy & $2.20(1.83-2.65)$ & $1.43(1.02-2.01)$ & $1.62(1.14-2.32)$ & $1.48(1.02-2.17)$ \\
\hline Operation duration $>180 \mathrm{~min}$ & $1.62(1.34-1.94)$ & $1.01(0.74-1.38)$ & $1.23(0.87-1.75)$ & - \\
\hline POD 0 IV fluids $<3 \mathrm{~L}$ & $1.27(1.06-1.52)$ & $0.95(0.70-1.27)$ & $0.99(0.69-1.41)$ & - \\
\hline POD 2 weight gain $>2.5 \mathrm{~kg}$ & $1.80(1.38-2.34)$ & $1.70(1.26-2.30)$ & $1.19(0.72-1.95)$ & - \\
\hline Index hospital stay $<3$ days & $0.61(0.51-0.74)$ & $0.91(0.67-1.23)$ & $0.90(0.63-1.29)$ & $1.14(0.78-1.65)$ \\
\hline Reoperation (index) & $10.32(7.87-13.5)$ & $11.36(7.36-17.5)$ & $5.71(3.73-8.75)$ & $5.87(3.76-9.15)$ \\
\hline
\end{tabular}

Uni- and multivariable risk factors for any readmission $(n=526)$ and early readmission within 48 hours of discharge $(n=128)$. Numbers are presented as odds ratio and $95 \%$ confidence intervals (in parentheses). Bold characters indicate significant values $(p<0.05)$.

$\mathrm{IV}=$ intravenous; $\mathrm{POD}=$ postoperative day; $\mathrm{SSI}=$ surgical site infection

was $30 \%$, the rate was $6 \%$ in patients with uncomplicated recovery. In the present study, readmissions seemed to be a consequence of a complicated postoperative course rather than the type or extent of surgery. Because of the potential co-occurrence of complications, patients with complicated recovery and undergoing reoperation are

\section{TABLE 4. Reasons for readmission}

\begin{tabular}{|c|c|c|c|c|}
\hline Type of complication & $\begin{array}{l}\text { All readmissions } \\
\quad(n=526)\end{array}$ & $\begin{array}{c}\text { Readmission }<48 h \\
\quad(n=128)\end{array}$ & $\begin{array}{c}\text { Readmission }>48 h \\
\quad(n=398)\end{array}$ & $p$ \\
\hline Surgical complications, n (\%) & $339(64.4)$ & $88(68.8)$ & $251(63.1)$ & 0.288 \\
\hline Postoperative ileus, n (\%) & $102(19.4)$ & 49 (38.3) & $53(13.3)$ & $<0.001$ \\
\hline SBO, n (\%) & $16(3)$ & $7(5.5)$ & $9(2.3)$ & 0.066 \\
\hline Bleeding/pelvic hematoma, $\mathrm{n}(\%)$ & $37(7)$ & $10(7.8)$ & $27(6.8)$ & 0.693 \\
\hline $\mathrm{SSI}, \mathrm{n}(\%)$ & $117(22.2)$ & $10(7.8)$ & $107(26.9)$ & $<0.001$ \\
\hline Superficial incisional & $40(7.6)$ & $5(3.9)$ & $35(8.8)$ & 0.084 \\
\hline Deep incisional & $8(1.5)$ & 0 & $8(2)$ & 0.209 \\
\hline Organ space & $70(13.3)$ & $5(3.9)$ & $65(16.3)$ & $<0.001$ \\
\hline Wound dehiscence, $\mathrm{n}(\%)$ & $30(5.7)$ & $3(2.3)$ & $27(6.8)$ & 0.077 \\
\hline Anastomotic leak, n (\%) & $35(6.7)$ & $8(6.3)$ & $27(6.8)$ & 1.000 \\
\hline Bowel perforation (nonanastomotic site), $\mathrm{n}(\%)$ & $7(1.3)$ & $3(2.3)$ & $4(1)$ & 0.369 \\
\hline Medical complications, $\mathrm{n}(\%)$ & $161(30.6)$ & $34(26.6)$ & $127(31.9)$ & 0.272 \\
\hline Dehydration/high stoma output & $57(10.8)$ & $8(6.3)$ & $49(12.3)$ & 0.071 \\
\hline Abdominal pain & $39(7.4)$ & $10(7.8)$ & $29(7.2)$ & 0.847 \\
\hline AKI & $20(3.8)$ & 0 & $20(5)$ & 0.006 \\
\hline Cardiac & $17(3.2)$ & $8(6.3)$ & $9(2.3)$ & 0.040 \\
\hline Thromboembolic event & $12(2.3)$ & $2(1.6)$ & $10(2.5)$ & 0.739 \\
\hline UTI & $16(3)$ & $3(2.3)$ & $13(3.3)$ & 0.772 \\
\hline Pneumonia & $7(1.3)$ & $1(0.8)$ & $6(1.5)$ & 1.000 \\
\hline Clostridium difficile colitis & $8(1.5)$ & $3(2.3)$ & $5(1.3)$ & 0.410 \\
\hline Infectious complications, n (\%) & $188(35.7)$ & $28(21.9)$ & $160(40.2)$ & $<0.001$ \\
\hline Surgical infectious & $158(30)$ & $21(16.4)$ & $137(34.4)$ & $<0.001$ \\
\hline Medical infectious & $31(5.9)$ & $7(5.5)$ & $24(6)$ & 1.000 \\
\hline Other reasons, $\mathrm{n}(\%)$ & $35(6.7)$ & $9(7)$ & $26(6.5)$ & 0.840 \\
\hline Major complications (Clavien IIIb-V), n (\%) & $134(25.5)$ & $28(21.9)$ & $106(26.6)$ & 0.297 \\
\hline Reoperation, $\mathrm{n}(\%)$ & $71(13.5)$ & 19 (14.8) & $52(13.1)$ & 0.609 \\
\hline
\end{tabular}

Medical conditions and surgical, medical, and infectious complications leading to early ( $<48$ hours after discharge, $\mathrm{n}=128)$ and late $(>48$ hours, $\mathrm{n}=389$ ) readmissions. $\mathrm{AKI}=$ acute kidney injury; $\mathrm{SBO}=$ small-bowel obstruction; SSI = surgical site infection; UTI = urinary tract infection. 


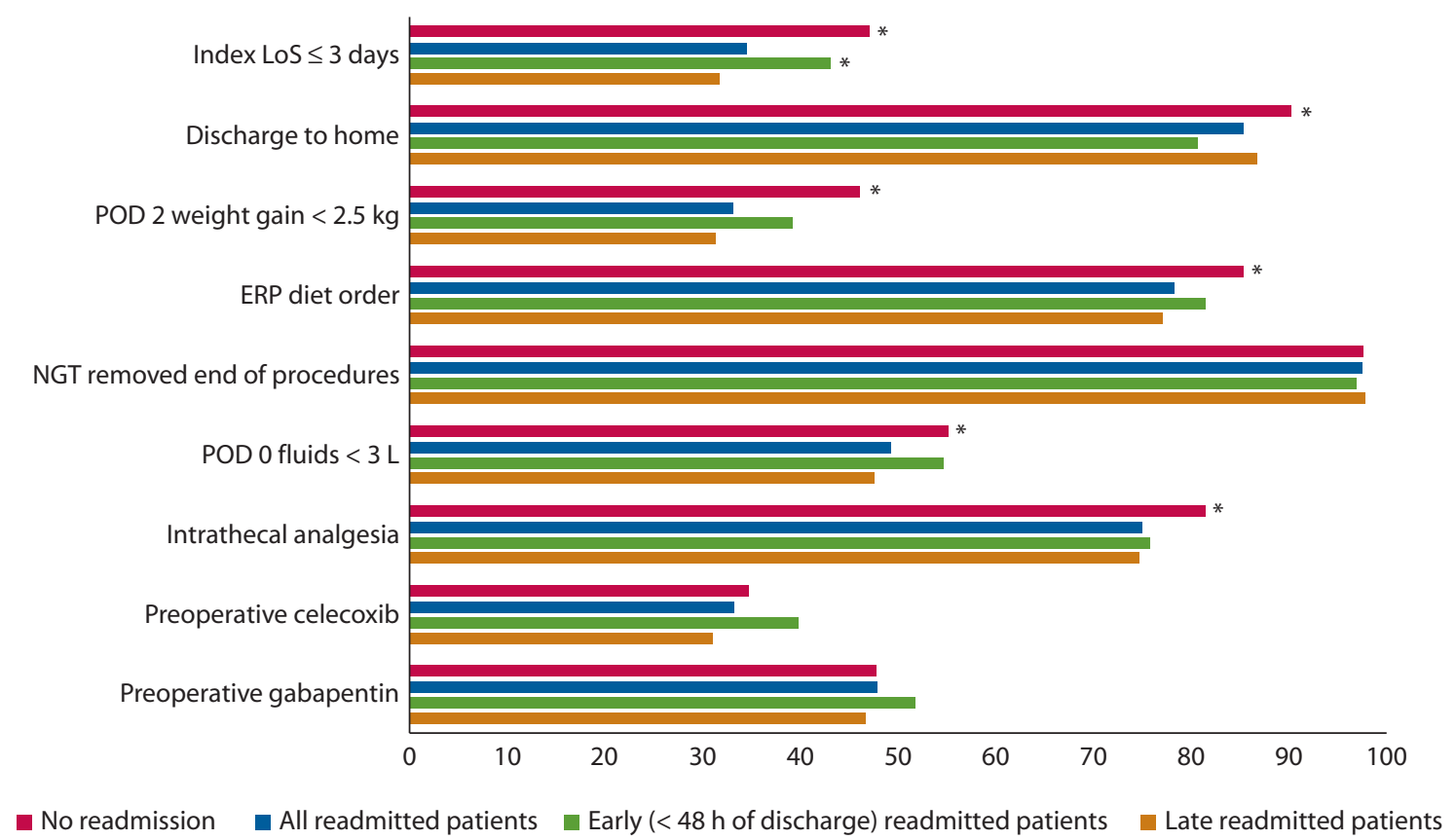

FIGURE 1. Enhanced recovery pathway compliance. Compliance (\%) to specific ERP-related items. Compared are patients without readmission ( $n=3678$, red bars) to all readmitted patients $(n=526$, blue bars) and early readmitted patients (within 48 hours of discharge, $n=128$, green bars) to patients readmitted after 48 hours $(n=398$, orange bars). ERP = enhanced recovery pathway; LoS = length of stay; $\mathrm{NGT}=$ nasogastric tube; POD = postoperative day. ${ }^{*}$ Indicates statistical significance $(p<0.05)$. Systematic implementation of preoperative celecoxib and gabapentin as per January 2014.

particularly prone to postoperative ileus and surgical infections, both of which were prevailing causes of readmission in the present cohort. ${ }^{31}$

Predictive scores of varying complexity and specificity have been developed to assess the risk of readmission; however, when applied to hospital-based, independent data, several existing models failed to reliably predict 30day readmissions. ${ }^{7}$ Thus, the present study aimed to address the scarcity of large, yet institutionally derived and specific, independent data to assess hospital readmissions, considering that the unique setting of a decentralized high-volume institution with nationwide patient accrual may not be representative for other institutions. It is important to note that a rather high rate of $3 \%$ early readmissions within 48 hours of discharge was observed. The prevailing reason for these early readmissions was postoperative ileus, consistent with previous reports, which however assessed early readmissions within a 5-day window of discharge. ${ }^{5,32}$ This is remarkable considering the focus on ileus-preventing measures and the strict application of predefined discharge criteria (including tolerance of normal diet) in the setting of the highly standardized institutional ERP and emphasizes the multifactorial and not entirely elucidated pathogenesis of paralytic ileus. ${ }^{33}$ Whether later discharge in these patients could prevent ileus occurrence remains questionable; however, careful assessment of potential ileus-related symptoms before discharge is certainly important and may warrant further observation in selected patients.
Unique patterns in early readmitted patients were not observed. Surgical site infection, in particular, organ space infection, was the main indication for hospital readmission beyond 48 hours. Although superficial SSIs may be successfully managed by primary care providers, the high rate of deep SSIs among readmitted patients reflects a challenging and invasive management problem. ${ }^{34,35} \mathrm{In}$ approximately $15 \%$, dehydration due to high stoma output and associated acute kidney injury were leading medical causes for late readmission, providing potential explanations for higher readmission rates after total colectomies and rectal resections. Consistent with our findings, a recent study revealed ileostomy as an independent predictor of readmission, with and without ERP as a standard of care, emphasizing the importance of close follow-up of these patients. ${ }^{36}$ Enhanced pre- and postdischarge stoma care-related education by dedicated care teams and protocols to prevent dehydration could help reduce stomarelated readmissions further.

The present study has limitations beyond its retrospective design. Both pre- and postoperative laboratory values were inconsistently assessed in the setting of these elective procedures and thus not retained for further analyses. In particular, a potential predictive value of postoperative values (eg, hemoglobin or inflammatory markers) in predicting readmissions should be considered for future studies. Because of the large sample size, statistically significant factors need to be put into the perspective of clinical significance. This holds particularly true for differences 
in preoperative laboratory values or the observed difference in length of index stay. An inherent circumstance of large high-volume referral institutions is loss to follow-up, bearing a risk of underreporting. Despite use of prospective administrative data, 30-day follow-up could not be completed in $6.2 \%$ of all patients. This needs to be considered when interpreting the results. The present study focused on rate, reasons, and risk factors for unplanned readmission, whereas further specifics (ie, emergency department visit or inpatient stay, length of readmission stay) were not specifically assessed. To address the severity of readmission, readmissions were further stratified according to complication profile (Clavien-Dindo grading scale). Twenty-five percent of readmissions had important implications according to this stratification. Despite the independent assessment of 30-day complications and complications that led to readmissions, some overlap may exist considering potential co-occurrence of complications. A broad range of conditions leading to readmission was revealed, which impeded further subgroup analysis due to the small sample size of specific outcomes. However, this single-center experience reports on a large, unselected, and consecutive ERP cohort undergoing major colorectal resections to provide a "real life" picture.

\section{CONCLUSIONS}

This study adds to the growing body of evidence that short hospital stay does not increase readmission rates in patients treated according to standardized perioperative enhanced recovery principles that include predefined discharge criteria. ${ }^{36,37}$ Readmissions seemed to be strongly associated with index stay-related adverse events rather than demographic or surgical risk factors in this series. A suspicious attitude toward potential ileus-related symptoms before discharge and dedicated education for ostomy patients are of utmost importance.

\section{REFERENCES}

1. Greer NL, Gunnar WP, Dahm P, et al. enhanced recovery protocols for adults undergoing colorectal surgery: a systematic review and meta-analysis. Dis Colon Rectum. 2018;61:1108-1118.

2. Greco M, Capretti G, Beretta L, Gemma M, Pecorelli N, Braga M. Enhanced recovery program in colorectal surgery: a meta-analysis of randomized controlled trials. World J Surg. 2014;38:1531-1541.

3. Zhuang CL, Ye XZ, Zhang XD, Chen BC, Yu Z. Enhanced recovery after surgery programs versus traditional care for colorectal surgery: a meta-analysis of randomized controlled trials. Dis Colon Rectum. 2013;56:667-678.

4. Bliss LA, Maguire LH, Chau Z, et al. Readmission after resections of the colon and rectum: predictors of a costly and common outcome. Dis Colon Rectum. 2015;58:1164-1173.

5. Al-Mazrou AM, Suradkar K, Mauro CM, Kiran RP. Characterization of readmission by day of rehospitalization after colorectal surgery. Dis Colon Rectum. 2017;60:202-212.
6. Bartlett EK, Hoffman RL, Mahmoud NN, Karakousis GC, Kelz RR. Postdischarge occurrences after colorectal surgery happen early and are associated with dramatically increased rates of readmission. Dis Colon Rectum. 2014;57:1309-1316.

7. Brauer DG, Lyons SA, Keller MR, Mutch MG, Colditz GA, Glasgow SC. Simplified risk prediction indices do not accurately predict 30-day death or readmission after discharge following colorectal surgery. Surgery. 2019;165:882-888.

8. Rattan R, Parreco J, Lindenmaier LB, et al. Underestimation of unplanned readmission after colorectal surgery: a national analysis. J Am Coll Surg. 2018;226:382-390.

9. Larson DW, Lovely JK, Cima RR, et al. Outcomes after implementation of a multimodal standard care pathway for laparoscopic colorectal surgery. Br J Surg. 2014;101:1023-1030.

10. Lovely JK, Maxson PM, Jacob AK, et al. Case-matched series of enhanced versus standard recovery pathway in minimally invasive colorectal surgery. Br J Surg. 2012;99:120-126.

11. Khreiss W, Huebner M, Cima RR, et al. Improving conventional recovery with enhanced recovery in minimally invasive surgery for rectal cancer. Dis Colon Rectum. 2014;57:557-563.

12. Grass F, Lovely JK, Crippa J, Mathis KL, Hübner M, Larson DW. Early acute kidney injury within an established enhanced recovery pathway: uncommon and transitory. World J Surg. 2019;43:1207-1215.

13. Lovely JK, Larson DW, Quast JM. A clinical practice agreement between pharmacists and surgeons streamlines medication management. Jt Comm J Qual Patient Saf. 2014;40:296-302.

14. Thiele RH, Raghunathan K, Brudney CS, et al; Perioperative Quality Initiative (POQI) I Workgroup. American Society for Enhanced Recovery (ASER) and Perioperative Quality Initiative (POQI) joint consensus statement on perioperative fluid management within an enhanced recovery pathway for colorectal surgery. Perioper Med (Lond). 2016;5:24.

15. Hübner M, Lovely JK, Huebner M, Slettedahl SW, Jacob AK, Larson DW. Intrathecal analgesia and restrictive perioperative fluid management within enhanced recovery pathway: hemodynamic implications. J Am Coll Surg. 2013;216:1124-1134.

16. Grass F, Hübner M, Lovely JK, Crippa J, Mathis KL, Larson DW. Ordering a normal diet at the end of surgery-justified or overhasty? Nutrients. 2018;10:1758.

17. Emori TG, Culver DH, Horan TC, et al. National nosocomial infections surveillance system (NNIS): description of surveillance methods. Am J Infect Control. 1991;19:19-35.

18. Merchea A, Lovely JK, Jacob AK, et al. Efficacy and outcomes of intrathecal analgesia as part of an enhanced recovery pathway in colon and rectal surgical patients. Surg Res Pract. 2018;2018:8174579.

19. Lemini R, Spaulding AC, Naessens JM, et al. ERAS protocol validation in a propensity-matched cohort of patients undergoing colorectal surgery. Int J Colorectal Dis. 2018;33:1543-1550.

20. Dindo D, Demartines N, Clavien PA. Classification of surgical complications: a new proposal with evaluation in a cohort of 6336 patients and results of a survey. Ann Surg. 2004;240:205-213.

21. Berian JR, Ban KA, Liu JB, Ko CY, Feldman LS, Thacker JK. Adherence to enhanced recovery protocols in NSQIP and association with colectomy outcomes. Ann Surg. 2019;269:486-493.

22. Favini N, Hockenberry JM, Gilman M, et al. Comparative trends in payment adjustments between safety-net and other hospitals since the introduction of the Hospital Readmis- 
sion Reduction Program and value-based purchasing. JAMA. 2017;317:1578-1580.

23. Joynt KE, Figueroa JE, Oray J, Jha AK. Opinions on the Hospital Readmission Reduction Program: results of a national survey of hospital leaders. Am J Manag Care. 2016;22:e287-e294.

24. Mehtsun WT, Papanicolas I, Zheng J, Orav EJ, Lillemoe KD, Jha AK. National trends in readmission following inpatient surgery in the Hospital Readmissions Reduction Program era. Ann Surg. 2018;267:599-605.

25. Wick EC, Shore AD, Hirose $\mathrm{K}$, et al. Readmission rates and cost following colorectal surgery. Dis Colon Rectum. 2011;54:1475-1479.

26. Damle RN, Cherng NB, Flahive JM, et al. Clinical and financial impact of hospital readmissions after colorectal resection: predictors, outcomes, and costs. Dis Colon Rectum. 2014;57:1421-1429.

27. Zafar SN, Shah AA, Channa H, Raoof M, Wilson L, Wasif N. Comparison of rates and outcomes of readmission to index vs nonindex hospitals after major cancer surgery. JAMA Surg. 2018;153:719-727.

28. Bennedsen ALB, Eriksen JR, Gögenur I. Prolonged hospital stay and readmission rate in an enhanced recovery after surgery cohort undergoing colorectal cancer surgery. Colorectal Dis. 2018;20:1097-1108.

29. Turina M, Remzi FH, Dietz DW, et al. Quantification of risk for early unplanned readmission after rectal resection: a singlecenter study. J Am Coll Surg. 2013;217:200-208.

30. Lucas DJ, Haider A, Haut E, et al. Assessing readmission after general, vascular, and thoracic surgery using ACS-NSQIP. Ann Surg. 2013;258:430-439.
31. Venara A, Alfonsi P, Cotte E, Loriau J, Hamel JF, Slim K; Francophone Group for Enhanced Recovery After Surgery (GRACE). Correction to: Postoperative ileus concealing intra-abdominal complications in enhanced recovery programs-a retrospective analysis of the GRACE database. Int J Colorectal Dis. 2019;34:1509-1514.

32. Wood T, Aarts MA, Okrainec A, et al.; iERAS group. Emergency room visits and readmissions following Implementation of an Enhanced Recovery After Surgery (iERAS) program. J Gastrointest Surg. 2018;22:259-266.

33. Venara A, Neunlist M, Slim K, et al. Postoperative ileus: pathophysiology, incidence, and prevention. J Visc Surg. 2016;153:439-446.

34. Grass F, Martin D, Moulin E, Hahnloser D, Demartines N, Hübner M. Specific national surveillance program for organ space infections after colonic surgery. Surg Infect (Larchmt). 2019;20:373-377.

35. Martin D, Hübner M, Moulin E, et al. Timing, diagnosis, and treatment of surgical site infections after colonic surgery: prospective surveillance of 1263 patients. J Hosp Infect. 2018;100:393-399.

36. Shah PM, Johnston L, Sarosiek B, et al. Reducing readmissions while shortening length of stay: the positive impact of an enhanced recovery protocol in colorectal surgery. Dis Colon Rectum. 2017;60:219-227.

37. Lawrence JK, Keller DS, Samia H, et al. Discharge within 24 to 72 hours of colorectal surgery is associated with low readmission rates when using Enhanced Recovery Pathways. J Am Coll Surg. 2013;216:390-394. 